\title{
Application of CFD, Taguchi Method, and ANOVA Technique to Optimize Combustion and Emissions in a Light Duty Diesel Engine
}

\author{
Senlin Xiao, Wanchen Sun, Jiakun Du, and Guoliang Li \\ State Key Laboratory of Automotive Simulation and Control, Jilin University, Changchun 130022, China \\ Correspondence should be addressed to Wanchen Sun; sunwc@jlu.edu.cn
}

Received 9 April 2014; Accepted 11 July 2014; Published 24 July 2014

Academic Editor: Zhijun Zhang

Copyright (c) 2014 Senlin Xiao et al. This is an open access article distributed under the Creative Commons Attribution License, which permits unrestricted use, distribution, and reproduction in any medium, provided the original work is properly cited.

Some previous research results have shown that EGR (exhaust gas recirculation) rate, pilot fuel quantity, and main injection timing closely associated with engine emissions and fuel consumption. In order to understand the combined effect of EGR rate, pilot fuel quantity, and main injection timing on the $\mathrm{NO}_{x}$ (oxides of nitrogen), soot, and ISFC (indicated specific fuel consumption), in this study, CFD (computational fluid dynamics) simulation together with the Taguchi method and the ANOVA (analysis of variance) technique was applied as an effective research tool. At first, simulation model on combustion and emissions of a light duty diesel engine at original baseline condition was developed and the model was validated by test. At last, a confirmation experiment with the best combination of factors and levels was implemented. The study results indicated that EGR is the most influencing factor on $\mathrm{NO}_{x}$. In case of soot emission and ISFC, the greatest influence parameter is main injection timing. For all objectives, pilot fuel quantity is an insignificant factor. Furthermore, the engine with optimized combination reduces by at least $70 \%$ for $\mathrm{NO}_{x}, 20 \%$ in soot formation, and $1 \%$ for ISFC, in contrast to original baseline engine.

\section{Introduction}

Because of robust design and high thermal efficiency, diesel engines increasingly and widely are applied to many power equipments, including light duty, medium duty, and heavy duty vehicles $[1,2]$. However, under the pressure of environmental pollution and energy crisis, diesel engine performance is being continuously enhanced in order to pursue a higher power density, improve fuel economy, and reduce emissions characteristics to meet more stringent emissions regulations $[1,3-6]$.

There are many factors that will affect the combustion and emissions of diesel engines, due to the fact that the combustion process and emission formation are a process of complex physical and chemical action. Taguchi method is one of the efficient and cost-effective methods to parametric analysis and optimization performance of objectives with a remarkable decrease in number of trials and time involved [7-9]. Thus, the combination of test and Taguchi method is an effective way to investigate the effect of different factors in controlling the emissions and fuel economy $[1-3,10,11]$. However, the decreased experimental numbers still spend a lot of time and money.

On the other hand, current multidimensional CFD tools have become sufficiently mature to guide the design and development of more efficient and cleaner internal combustion engines [4]. Indeed, simulation models can provide insight into the fundamental processes occurring during combustion [12]. For example, Mobasheri et al. [13] successfully used a CFD simulation to explore the combined effects of pilot, post- and multiple-fuel injection strategies and EGR on engine performance and emission formation in a heavy duty DI-diesel engine. They found that injecting adequate fuel in postinjection at an appropriate EGR allows significant soot reduction without a $\mathrm{NO}_{x}$ penalty rate.

In addition, numerous studies have shown that EGR rate, pilot fuel quantity, and main injection timing associated with engine $\mathrm{NO}_{x}$, soot emissions and fuel consumption [1$3,10,11,13]$. It is necessary to conduct an in-depth study in order to understand these three factors on the relationship 


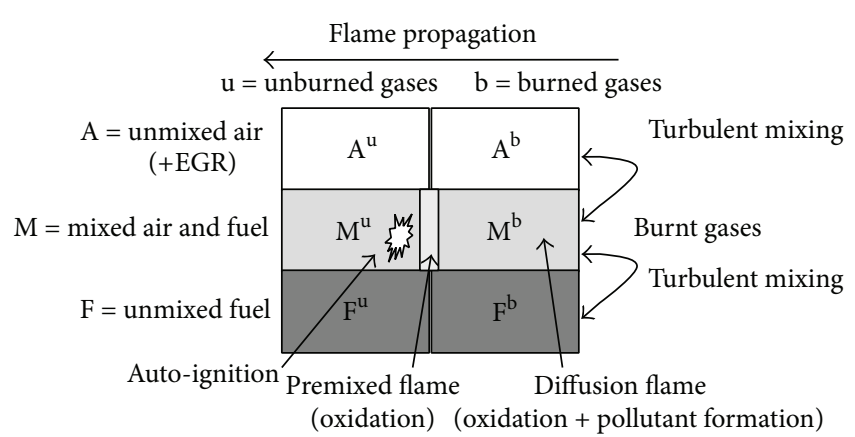

Figure 1: Principle of the ECFM3Z model.

with emissions and fuel consumption. Hence, in this study, CFD simulation together with the Taguchi method was used to investigate the combined effect of EGR rate, pilot fuel quantity, and main injection timing on the $\mathrm{NO}_{x}$, soot, and ISFC in a diesel engine at $2000 \mathrm{r} / \mathrm{min}, 50 \%$ load, with minimum number of experimental work. Moreover, for purpose of determining the effects of influencing factors on the objectives, the ANOVA technique was applied to analyze simulation results.

\section{Computational Procedure, Model Validation, and Methodology}

2.1. Computational Procedure. The multidimensional CFD calculations were carried out with the commercial CFD package AVL FIRE. The turbulent combustion model is ECFM-3Z (extended coherent flame model-3 zones), which includes a description of the local mixture stratification by considering three mixing zones (see Figure 1): the unmixed fuel zone $\mathrm{F}$, the mixed zone $\mathrm{M}$ containing fuel and air, and the unmixed air zone A. Each region is separated into two parts: unburned gases region and burned gases region [14, 15]. For turbulent combustion phenomena, the ECFM-3Z model uses a 2-step chemistry mechanism for the fuel conversion like [16]

$$
\begin{gathered}
\mathrm{C}_{\alpha} \mathrm{H}_{\beta} \mathrm{O}_{\gamma}+\left(\alpha+\frac{\beta}{4}-\frac{\gamma}{2}\right) \mathrm{O}_{2} \longrightarrow \alpha \mathrm{CO}_{2}+\frac{\beta}{2} \mathrm{H}_{2} \mathrm{O} \\
\mathrm{C}_{\alpha} \mathrm{H}_{\beta} \mathrm{O}_{\gamma}+\left(\frac{\alpha}{2}-\frac{\gamma}{2}\right) \mathrm{O}_{2} \longrightarrow \alpha \mathrm{CO}+\frac{\beta}{2} \mathrm{H}_{2}
\end{gathered}
$$

where $\alpha, \beta$, and $\gamma$ are the atomic number of $\mathrm{C}, \mathrm{H}$, and $\mathrm{O}$ elements, respectively.

The $k-\zeta-f$ turbulent model is used for modeling turbulent flow in the combustion chamber. Hanjalić et al. developed this model. They proposed an eddy viscosity model based on the concept of Durbin's elliptic relaxation, which solves a transport equation for the velocity scales ratio $\zeta=\overline{v^{2}} / k$ instead of $\overline{v^{2}}$, thus increasing the robustness of the model, reducing the sensitivity to nonuniform grids [17].

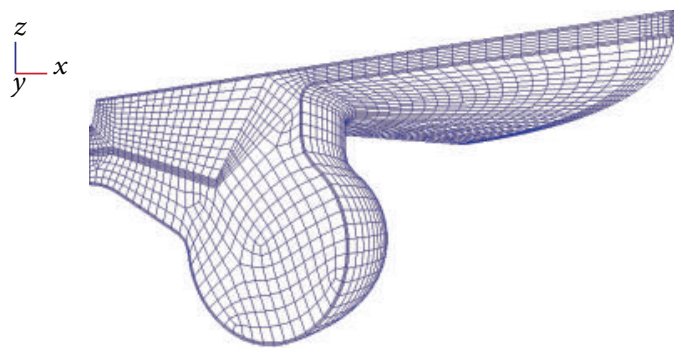

FIGURE 2: Mesh of the simulation model on the TDC.

TABLE 1: Computational submodels.

\begin{tabular}{ll}
\hline Breakup model & KH-RT model \\
Evaporation model & Dukowicz model \\
Collision model & Nordin model \\
Wall interaction model & Bai Gosman model \\
\hline
\end{tabular}

The extended Zeldovich mechanism is widely accepted as a successful method for predicting NO concentration. Chemical reactions are given by $[6,17]$

$$
\begin{gathered}
\mathrm{O}+\mathrm{N}_{2} \stackrel{\kappa_{1}}{\longleftrightarrow} \mathrm{NO}+\mathrm{N} \\
\mathrm{N}+\mathrm{O}_{2} \stackrel{\kappa_{2}}{\longleftrightarrow} \mathrm{NO}+\mathrm{N} \\
\mathrm{N}+\mathrm{OH} \stackrel{\kappa_{3}}{\longleftrightarrow} \mathrm{NO}+\mathrm{H}
\end{gathered}
$$

where $\kappa_{1}, \kappa_{2}$, and $\kappa_{3}$ are the rate of reaction; the unit is $\mathrm{cm}^{3} / \mathrm{mol} \cdot \mathrm{s}$.

The Soot emission is calculated using the kinetic model, which contains a reduced number of species and reactions and has been developed in order to provide a computationally efficient kinetic overall soot model [16]. Table 1 presents several submodels used in present simulation model $[13,18]$.

Because of the symmetry of the combustion chamber and the injector at the center of the combustion chamber has 6 nozzle holes, the simulations were performed on one sixth of the combustion chamber for reducing calculation time. The mesh of the simulation model on the top dead center was shown in Figure 2.

2.2. Model Validation. The engine used in this study was a light duty, 4 cylinders, four stroke, turbocharging, watercooled diesel engine. Specifications of simulated engine were listed in Table 2. The experimental system was shown in Figure 3. The in-cylinder pressure was measured using a Kistler 6125B quartz crystal pressure sensor and an ONO SOKKI DS-9100 Combustion analyzer was used to analyze the in-cylinder pressure. The $\mathrm{NO}_{x}$ emissions were measured with a HORIBA MEXA-7100D exhaust gas analyzer. Smoke was measured by smoke meter.

The simulated original baseline condition of light duty diesel engine was actuated at $2000 \mathrm{r} / \mathrm{min}, 50 \%$ load with a pilot injection included in injection strategy. Table 3 lists initial conditions and input parameters for simulation. 


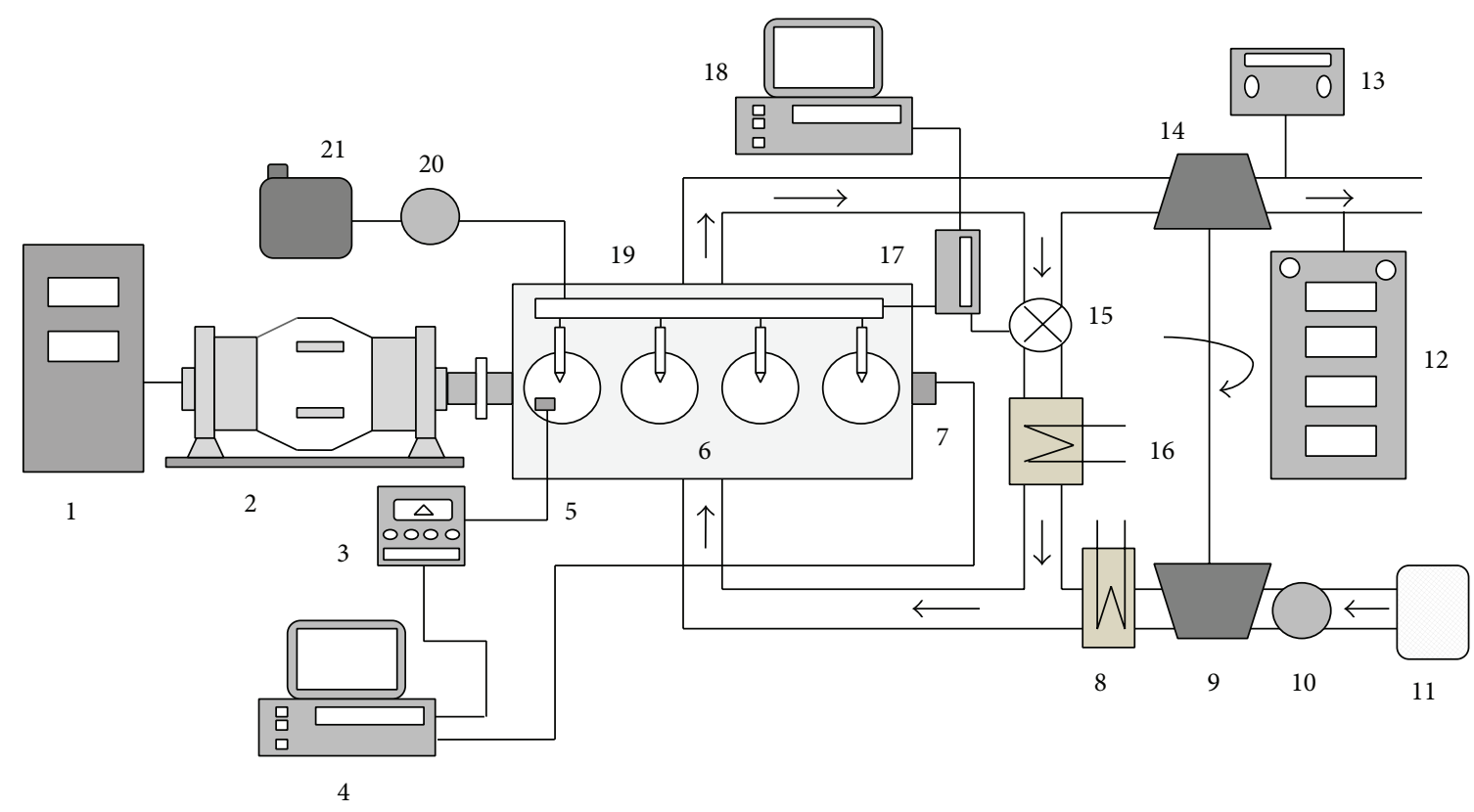

FIGURE 3: Schematic of experimental setup. (1) Dynamometer controller; (2) dynamometer; (3) charge amplifier; (4) PC control; (5) pressure sensor; (6) engine; (7) encoder; (8) intake cooler; (9) Compressor; (10) gas flow meter; (11) air cleaner; (12) exhaust gas analyzer; (13) smoke meter; (14) turbine; (15) EGR valve; (16) EGR cooler; (17) ECU; (18) PC control; (19) common rail; (20) fuel flow meter; (21) fuel tank.

TABLE 2: Engine specifications.

\begin{tabular}{lc}
\hline Bore $(\mathrm{mm})$ & 93 \\
Stroke $(\mathrm{mm})$ & 102 \\
Compression ratio & 17.2 \\
Swirl ratio & 2 \\
Number of nozzle holes & 6 \\
Number of cylinders & 4 \\
Displacement $(\mathrm{L})$ & 2.771 \\
Intake valve closure $(\mathrm{CAD})$ & 595 \\
Exhaust valve opening (CAD) & 846 \\
\hline
\end{tabular}

TABLE 3: Calculation conditions.

\begin{tabular}{lc}
\hline Intake temperature (IVC) (K) & 330 \\
Intake pressure (IVC) (MPa) & 0.151 \\
Engine speed (r/min) & 2000 \\
EGR rate & $7 \%$ \\
Start of pilot injection $\left({ }^{\circ}\right.$ BTDC) & 19 \\
Start of main injection $\left({ }^{\circ}\right.$ ATDC) & 1 \\
Fuel injection quantity (mg/cycle) & 25 \\
\hline
\end{tabular}

TDC (top dead center) on the compression stroke was defined as $720 \mathrm{CAD}$ (crank angle degree). To ensure the intake air mass amount was equal to the actual quantity of inlet air, the intake air temperature obtained after several adjustments was set to $330 \mathrm{~K}$ at IVC (intake valve closure). The well-justified assumptions were applied such that an entire piston surface, cylinder head, and cylinder wall are at constant temperature. Constant temperature of $500 \mathrm{~K}$ was used for the piston surface and cylinder head, and $400 \mathrm{~K}$ was used for the cylinder wall. From Figures 4 and 5, it can be seen that good agreement was achieved between experimental and simulation results. Although there are still some differences between simulation and test, Mobasheri et al. [13] considered that these variances related to testing uncertainties in input parameters for the simulations, for instance, the precise injection duration, start of injection timing, and gas temperature at intake valve closure.

2.3. Taguchi Method. Instead of having to test all possible combinations of design parameters, the Taguchi method tests the special combinations according to arrangements of orthogonal arrays (OA), in order to obtain the optimal combination and save time and expenses $[9,19,20]$. Another important feature of Taguchi method is the signal-to-noise $(S / N)$ ratio employed as a measure of the impact of noise factors on performance. In this study, EGR rate, pilot fuel quantity, and main injection timing were considered as the influencing factors. In addition, $\mathrm{NO}_{x}$ emission, soot emission, and ISFC are the response variables of the influencing factors. Therefore, the smaller-the-better characteristics of $S / N$ ratio are used in the present study. $S / N$ ratio is calculated as depicted in the following formula:

$$
S / N=-10 \log \frac{1}{n}\left(\sum_{i=1}^{n} y_{i}^{2}\right),
$$

where $y_{i}$ is the value of the quality characteristic measured from the test and $n$ is the number of experiments. The unit of $S / N$ ratio is $\mathrm{dB}[2,9,19,20]$.

In present study, a $\mathrm{L}_{9}$ orthogonal array for three factors and three levels was chosen and given in Table 4. The details of three levels of the chosen factors are given in Table 5. 
TABLE 4: Taguchi's $\mathrm{L}_{9}$ orthogonal arrays.

\begin{tabular}{lccc}
\hline $\begin{array}{l}\text { Trial } \\
\text { number }\end{array}$ & $\begin{array}{c}\text { Column 1 } \\
\text { (EGR rate) }\end{array}$ & $\begin{array}{c}\text { Column 2 } \\
\text { (pilot fuel } \\
\text { quantity) }\end{array}$ & $\begin{array}{c}\text { Column 3 } \\
\text { (main injection } \\
\text { timing) }\end{array}$ \\
\hline 1 & 1 & 1 & 1 \\
2 & 1 & 2 & 2 \\
3 & 1 & 3 & 3 \\
4 & 2 & 1 & 2 \\
5 & 2 & 2 & 3 \\
6 & 2 & 3 & 1 \\
7 & 3 & 1 & 3 \\
8 & 3 & 2 & 1 \\
9 & 3 & 3 & 2 \\
\hline
\end{tabular}

TABLE 5: Factors with chosen levels.

\begin{tabular}{lccc}
\hline \multirow{2}{*}{ Factors } & \multicolumn{3}{c}{ Levels of factors } \\
& 1 & 2 & 3 \\
\hline EGR rate & $7 \%$ & $17 \%$ & $27 \%$ \\
Pilot fuel quantity & $7.2 \%$ & $17.2 \%$ & $27.2 \%$ \\
Main injection timing & $4^{\circ} \mathrm{CA} \mathrm{BTDC}$ & $1^{\circ} \mathrm{CA}$ ATDC & $6^{\circ} \mathrm{CA}$ ATDC \\
\hline
\end{tabular}

In Table 4 columns 1, 2, and 3 represent the EGR rate, the pilot fuel quantity, and main injection timing, respectively.

EGR rate used in this work was calculated by the concentration of carbon dioxide in intake and exhaust gas through the following equation:

$$
\mathrm{EGR}=\frac{\left[\mathrm{CO}_{2}\right]_{\text {inlet }}}{\left[\mathrm{CO}_{2}\right]_{\text {exhaust }}} \times 100 \%
$$

Definition of pilot fuel quantity was the proportion of an existing fuel quantity in pilot injection, which accounted for the total cycle fuel injection quantity.

2.4. ANOVA Technique. ANOVA is an analytical method that identifies the factor which shows a large dispersion by analyzing the dispersion of the characteristic value of each factor [20]. In this study, the data from CFD simulation results based on the orthogonal arrays can be analyzed by performing analysis of variance to illustrate the degree of importance of each factor that prominently influenced the response variables $[11,19,20]$. The corresponding mathematical statements established with ANOVA for present study are given in (8), (9), (10), and (11). Equation (8) expresses the mean value of the overall $S / N$, where $k$ is the number of the trials. The sums of squares due to the variations of the overall mean (SS) is calculated by (9). The mean of the influencing factors $\left(\mathrm{SS}_{i}\right)$ is expressed as (10). The percentage contribution of the individual factors on the chosen response variables will

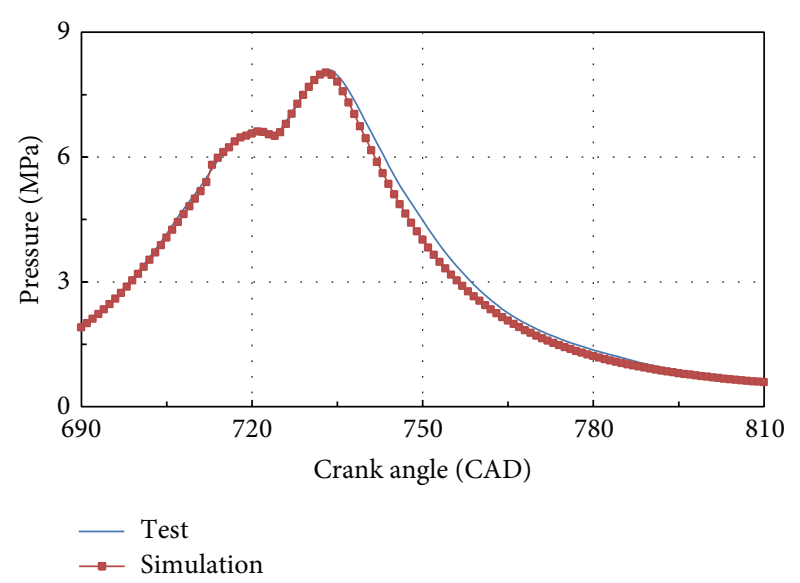

Figure 4: Comparison of calculated and measured on cylinder pressure.

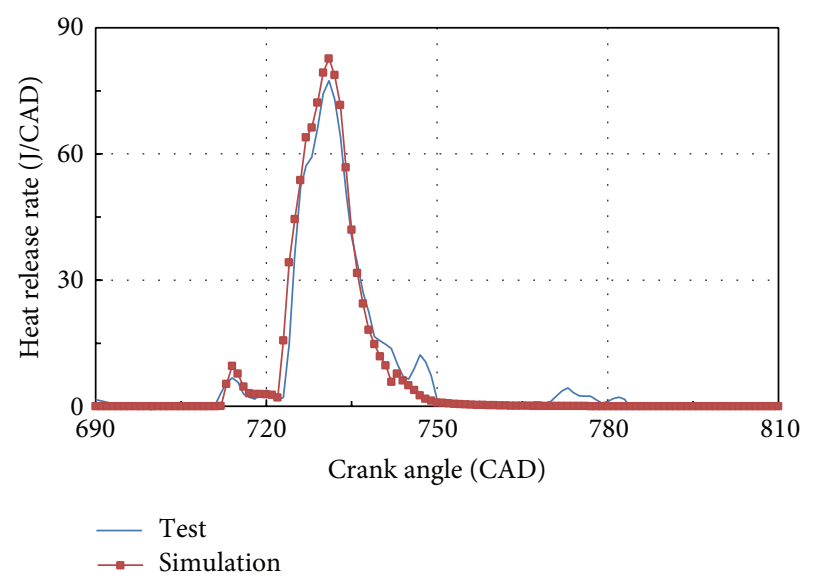

FIGURE 5: Comparison of calculated and measured on heat release rate.

be considered to decide the optimized combination and it is calculated through (11) as follows $[2,9,19,20]$ :

$$
\begin{gathered}
\overline{S / N}=\frac{1}{9} \sum_{k=1}^{9}(S / N)_{k}, \\
\mathrm{SS}=\sum_{i=1}^{9}\left((S / N)_{i j}-\overline{S / N}\right)^{2}, \\
\mathrm{SS}_{i}=\sum_{j=1}^{3}\left((S / N)_{i j}-\overline{S / N}\right)^{2} \\
\text { Contribution } \%=\frac{\mathrm{SS}_{i}}{\mathrm{SS}} \times 100 \% .
\end{gathered}
$$

\section{Results and Discussion}

3.1. CFD Computational Results. After conducting the CFD simulation with the combination of influencing factors from $\mathrm{L}_{9} \mathrm{OA}$, the computational results of response variables were shown in Table 1 . The results derived from the calculated mass 
TABLE 6: Calculated normalized results of response variables.

\begin{tabular}{lccc}
\hline Trial number & $\mathrm{NO}_{x}$ & Soot & ISFC \\
\hline 1 & 1.0876 & 0.5770 & 0.9822 \\
2 & 0.6593 & 0.8876 & 1.0000 \\
3 & 0.3268 & 1.8455 & 1.0251 \\
4 & 0.5788 & 1.0485 & 1.0042 \\
5 & 0.3426 & 1.8547 & 1.0356 \\
6 & 0.5966 & 0.6473 & 0.9942 \\
7 & 0.2403 & 2.2587 & 1.0592 \\
8 & 0.2637 & 0.7622 & 0.9906 \\
9 & 0.1129 & 1.5820 & 1.0079 \\
\hline
\end{tabular}

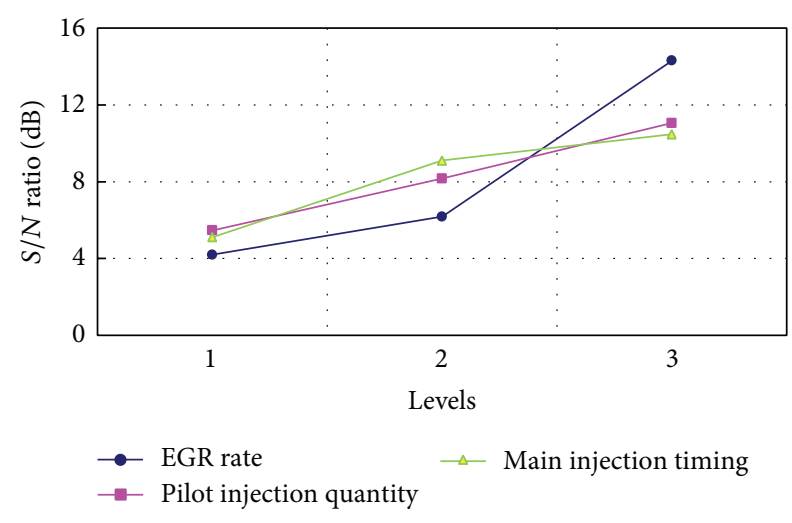

Figure 6: $S / N$ response curves for $\mathrm{NO}_{x}$.

formation divided by the calculated IMEP (indicated mean effective pressure), then they were normalized as discussed by Hajireza et al. [21], in respect to the corresponding value for original baseline case in order to see a comparable result.

3.2. Analysis of $S / N$ Response Curves. Table 7 shows the $S / N$ ratios for each factor computed in the Taguchi process and based on the results of Table 6. From the Table 7, the combination which has the maximum $S / N$ ratio was considered as the best combination in achieving the optimum objective since as the assessment of quality characteristics, the larger $S / N$ value, and the better results of response variables [11]. The $S / N$ response curves are graphical expressions of change in response variables with the variation in influencing factor level. The Figures 6, 7, and 8 show the response curves of Taguchi experiment. In fact, $S / N$ ratio in Figures 6,7 , and 8 is the value of corresponding $(S / N)_{i j}$, which have considered the mean effect of each levels in each factor. $U, V$, and $W$ in Tables 7 and 8 represent EGR rate, pilot fuel quantity, and main injection timing, respectively.

As it can be seen from Figure 6, the peak point of each factor occurs at the EGR rate of $27 \%$, pilot fuel quantity of $27.2 \%$, and main injection timing of $6^{\circ} \mathrm{CA}$ ATDC (after top dead center), respectively. It is obvious that the $S / N$ ratio of factor EGR rate varies largely and three factors show a consistent trend in affecting the $\mathrm{NO}_{x}$ varying with the level. The reason is that EGR has been proved to be a very effective $\mathrm{NO}_{x}$ reduction technique and retarded main

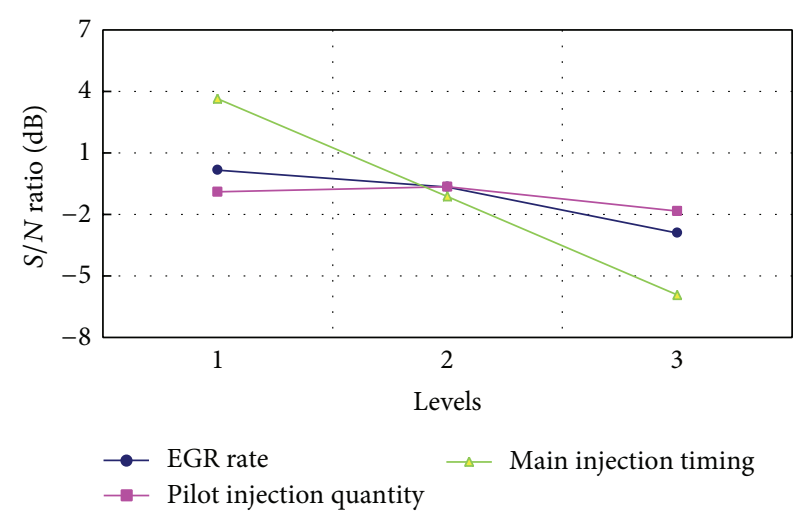

FIgURE 7: $S / N$ response curves for soot.

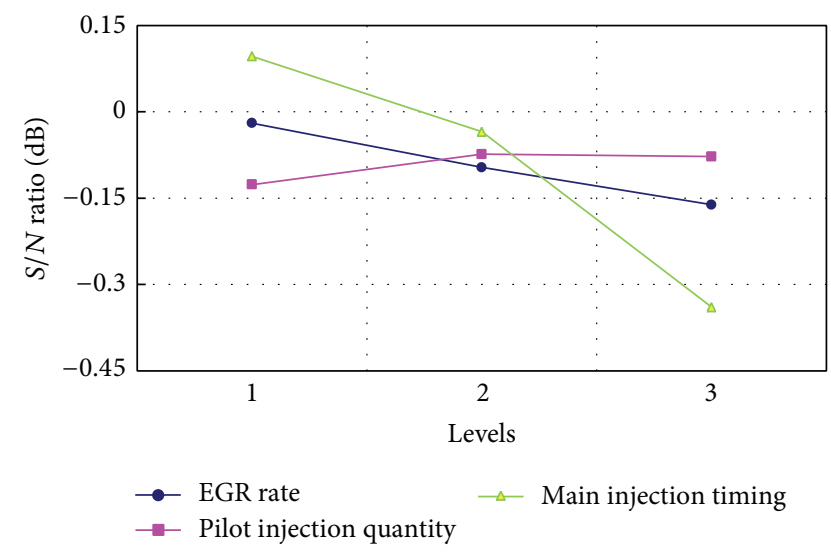

FIGURE 8: $S / N$ response curves for ISFC.

injection timing decreases in-cylinder peak heat release rate and peak temperature, which lead to a reduction in $\mathrm{NO}_{x}$ [22]. As for pilot injection, it can shorten the ignition delay and raise the in-cylinder temperature before main combustion, thus avoiding the rapid heat release rate and increasing the gas temperature too quickly. Accordingly, the $\mathrm{NO}_{x}$ emissions, which have a close relationship with temperature, can be reduced [23]. For further analysis and discussion we will draw on ANOVA technique in the following sections.

It is observed from Figure 7 that the optimum factors are at $7 \%$ EGR rate, $17.2 \%$ pilot fuel quantity and $4^{\circ} \mathrm{CA}$ BTDC (Before Top Dead Center) main injection timing. For pilot fuel quantity, the maximum $S / N$ ratio in Figures 7 and 8 appears in corresponding point that at level 2. This illustrates that it is necessary to choose proper pilot fuel quantity for optimizing combustion process in-cylinder. Since the change in pilot fuel quantity changes the fuel concentration distribution, this may result in two different effects, either enhancing or deteriorating fuel-air mixing [24]. In addition, it is found that EGR rate and main injection timing have the same effect for soot emissions. In other words, with EGR rate increasing and main injection timing retarding, the soot emissions increased. It is also illustrated that EGR and main injection timing have a contrary influence for soot emissions as compared to $\mathrm{NO}_{x}$ emissions. This effect is attributed to the introduced high level EGR in combustion 
TABLE 7: $S / N$ ratio results.

\begin{tabular}{|c|c|c|c|c|c|c|c|c|}
\hline \multirow{2}{*}{$\begin{array}{l}\text { Factors } \\
(i)\end{array}$} & \multirow{2}{*}{$\begin{array}{l}\text { Levels } \\
(j)\end{array}$} & \multirow{2}{*}{$\begin{array}{l}\text { Trial number } \\
\qquad(k)\end{array}$} & \multicolumn{3}{|c|}{$S / N$ ratio } & \multicolumn{3}{|c|}{$(S / N)_{i j}$} \\
\hline & & & $\mathrm{NO}_{x}$ & Soot & ISFC & $\mathrm{NO}_{x}$ & Soot & ISFC \\
\hline \multirow{9}{*}{$U$} & \multirow{3}{*}{$7 \%$} & 1 & -0.7297 & 4.7766 & 0.1561 & 4.2013 & 0.1633 & -0.0199 \\
\hline & & 2 & 3.6189 & 1.0356 & 0.0000 & & & \\
\hline & & 3 & 9.7148 & -5.3225 & -0.2157 & & & \\
\hline & \multirow{3}{*}{$17 \%$} & 4 & 4.7500 & -0.4114 & -0.0363 & 6.1800 & -0.6665 & -0.0967 \\
\hline & & 5 & 9.3041 & -5.3657 & -0.3040 & & & \\
\hline & & 6 & 4.4859 & 3.7776 & 0.0502 & & & \\
\hline & \multirow{3}{*}{$27 \%$} & 7 & 12.3834 & -7.0773 & -0.4995 & 14.3029 & -2.9007 & -0.1617 \\
\hline & & 8 & 11.5794 & 2.3591 & 0.0823 & & & \\
\hline & & 9 & 18.9458 & -3.9839 & -0.0680 & & & \\
\hline \multirow{9}{*}{$V$} & \multirow{3}{*}{$7.20 \%$} & 1 & -0.7297 & 4.7766 & 0.1561 & 5.4679 & -0.9040 & -0.1266 \\
\hline & & 4 & 4.7500 & -0.4114 & -0.0363 & & & \\
\hline & & 7 & 12.3834 & -7.0773 & -0.4995 & & & \\
\hline & \multirow{3}{*}{$17.20 \%$} & 2 & 3.6189 & 1.0356 & 0.0000 & 8.1674 & -0.6570 & -0.0739 \\
\hline & & 5 & 9.3041 & -5.3657 & -0.3040 & & & \\
\hline & & 8 & 11.5794 & 2.3591 & 0.0823 & & & \\
\hline & \multirow{3}{*}{$27.20 \%$} & 3 & 9.7148 & -5.3225 & -0.2157 & 11.0488 & -1.8429 & -0.0778 \\
\hline & & 6 & 4.4859 & 3.7776 & 0.0502 & & & \\
\hline & & 9 & 18.9458 & -3.9839 & -0.0680 & & & \\
\hline \multirow{9}{*}{$W$} & \multirow{3}{*}{$4^{\circ} \mathrm{CA}$ BTDC } & 1 & -0.7297 & 4.7766 & 0.1561 & 5.1118 & 3.6378 & 0.0962 \\
\hline & & 6 & 4.4859 & 3.7776 & 0.0502 & & & \\
\hline & & 8 & 11.5794 & 2.3591 & 0.0823 & & & \\
\hline & \multirow{3}{*}{$1^{\circ} \mathrm{CA}$ ATDC } & 2 & 3.6189 & 1.0356 & 0.0000 & 9.1049 & -1.1199 & -0.0348 \\
\hline & & 4 & 4.7500 & -0.4114 & -0.0363 & & & \\
\hline & & 9 & 18.9458 & -3.9839 & -0.0680 & & & \\
\hline & \multirow{3}{*}{$4^{\circ} \mathrm{CA}$ ATDC } & 3 & 9.7148 & -5.3225 & -0.2157 & 10.4674 & -5.9218 & -0.3397 \\
\hline & & 5 & 9.3041 & -5.3657 & -0.3040 & & & \\
\hline & & 7 & 12.3834 & -7.0773 & -0.4995 & & & \\
\hline
\end{tabular}

TABLE 8: Results of ANOVA.

\begin{tabular}{|c|c|c|c|c|c|c|c|c|}
\hline \multirow{2}{*}{ Factors } & \multirow{2}{*}{$\overline{S / N}$} & \multirow{2}{*}{ SS } & \multicolumn{3}{|c|}{$\mathrm{SS}_{i}$} & \multicolumn{3}{|c|}{ Contribution \% } \\
\hline & & & $\mathrm{NO}_{x}$ & Soot & ISFC & $\mathrm{NO}_{x}$ & Soot & ISFC \\
\hline$U$ & 8.228 & 274.32 & 57.3127 & 5.0226 & 0.0101 & 20.9 & 3.23 & 2.88 \\
\hline V & -1.1347 & 155.39 & 15.5789 & 0.783 & 0.0017 & 5.7 & 0.5 & 0.49 \\
\hline$W$ & -0.0928 & 0.3506 & 15.4943 & 45.693 & 0.1001 & 5.6 & 29.41 & 28.54 \\
\hline
\end{tabular}

chamber giving rise to the reduction in oxygen availability for fuel combustion, and the retarded main injection would weaken atomization and vaporization of the injected fuel; furthermore, those will lead to incomplete combustion and increase in soot emission [25].

Figure 8 shows plots of the $S / N$ ratio of ISFC against EGR rate, pilot fuel quantity, and main injection timing. As is seen, the results show the same trend as Figure 7. This means that the soot emissions and ISFC can be reduced simultaneously by selecting the same factors and levels.

3.3. Application of ANOVA. In order to determine the effects of influencing factors (pilot fuel quantity, EGR rate, and main injection timing) on the $\mathrm{NO}_{x}$ emissions, soot emissions, and ISFC of a light duty diesel engine, the ANOVA was carried out and the results were shown in Table 8 . Note that the calculation results of Table 8 depended on the results in Table 7.

As shown in the Table 8 , percentage contributions of EGR rate, pilot fuel quantity, and main injection timing were $20.9 \%, 5.7 \%$, and $5.6 \%$, respectively, for $\mathrm{NO}_{x}$ emissions. In the case of soot emissions, the percentage contributions of EGR rate, pilot fuel quantity, and main injection timing were $3.23 \%, 0.5 \%$, and $29.41 \%$ respectively. In addition, with regard to ISFC, percentage contributions of EGR rate, pilot fuel quantity, and main injection timing were $2.88 \%, 0.49 \%$, and $28.54 \%$, respectively. 


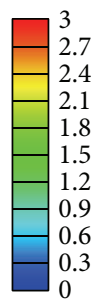

Specification

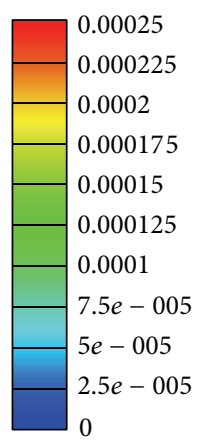

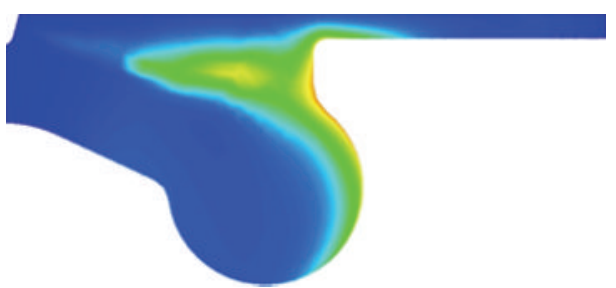

Equivalence ratio at end of the main injection (optimum)

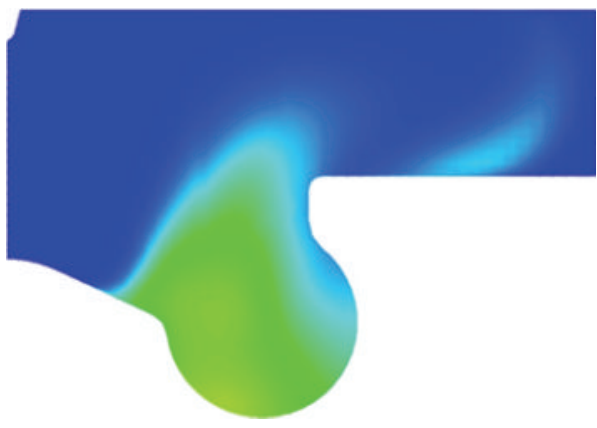

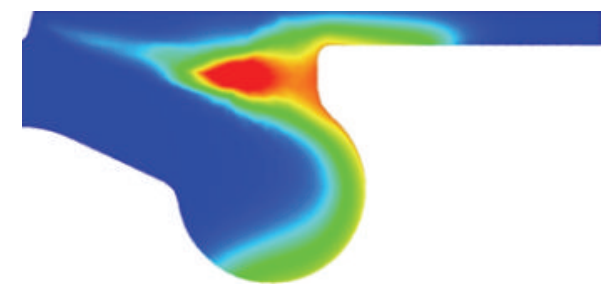

Equivalence ratio at end of the main injection (original)

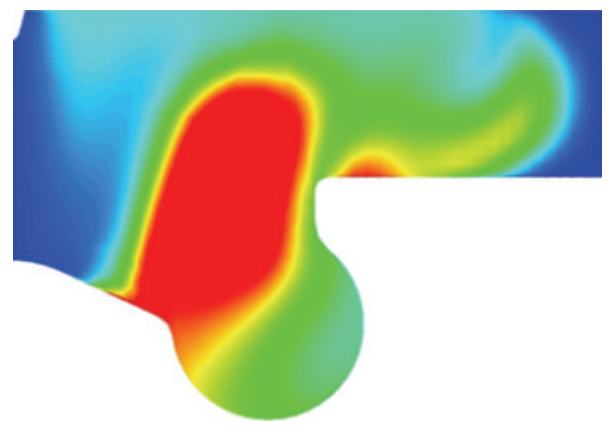

Specification In-cylinder $\mathrm{NO}_{x}$ distributions at 55, ATDC (optimum) In-cylinder $\mathrm{NO}_{x}$ distributions at 55, ATDC (original)

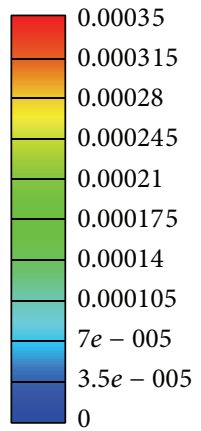

Specification

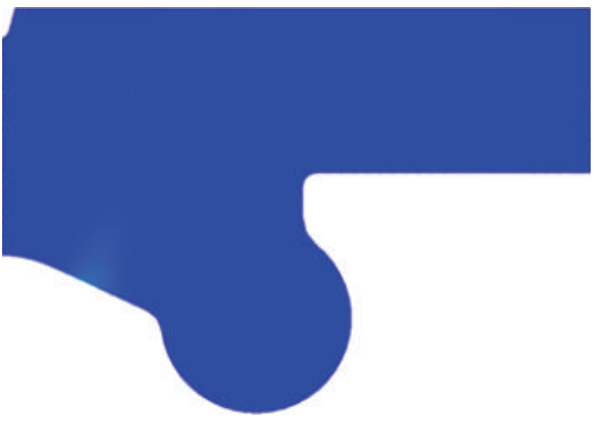

In-cylinder soot distributions at 55, ATDC (optimum)

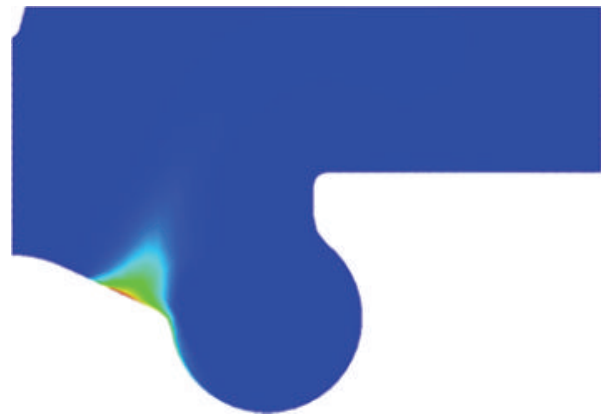

In-cylinder soot distributions at 55, ATDC (original)

FIgURE 9: Comparison of equivalence ratio and emission distributions between optimized and original case.

The main objective of percentage contributions is to analyze engine influencing parameters which significantly affect the performance characteristics. The larger value of percentage contributions means that the factor has a greater influence on the response variable. It can be observed that EGR is the most influencing factor on $\mathrm{NO}_{x}$. When compared with EGR, the other influencing parameters had slight influence for $\mathrm{NO}_{x}$ control, though retarded injection has been recognized as an effective way to reduce $\mathrm{NO}_{x}$ emissions by retarding the combustion phase which reduces the peak temperature in-cylinder resulting in suppressing the molecules of oxygen and nitrogen combine. Temperature and oxygen concentration play a crucial role in the formation of oxides of nitrogen. On the other hand, EGR can reduce the peak flame temperature and oxygen concentration at the same time. Those factors can further illustrate that, as compared to other influencing parameters, EGR is a very effective control technique for decreasing $\mathrm{NO}_{x}[1,26]$. In addition, the two parameters of pilot fuel quantity and main injection timing have approximately the same level of influence on the $\mathrm{NO}_{x}$ emissions, as shown in Table 8.

Based on Table 8, it also can be seen that the greatest influence of the soot and ISFC is exhibited main injection timing, then EGR rate, and pilot fuel quantity. In view of the fact that the percentage contributions of pilot fuel quantity is almost close to zero, it can be considered that pilot fuel quantity is almost insignificant in case of soot and ISFC, compared to main injection timing and EGR. This is because the pilot fuel quantity is smaller than the injected fuel in main injection, so the emissions caused by the pilot injection can be ignored in most cases and the total emissions simply relied on the main combustion [27].

3.4. Optimum Combination. Based on the analysis of $S / N$ response curves and results of ANOVA, it is concluded that in the case of $\mathrm{NO}_{x}$, EGR is the most influencing factor, the other influencing parameters have slight influence, 
and the best level is at level 3. However, main injection timing is the greatest effect in regard to soot and ISFC; the peak point $S / N$ ratio of this factor occurs at $4^{\circ} \mathrm{CA}$ BTDC. On the other hand, pilot fuel quantity is an insignificant influencing factor for all response variables, especially in terms of soot and ISFC. Hence, the optimum combination of factors and levels for the chosen response variables are at 27\% EGR rate, 27.2\% pilot fuel quantity, and $4^{\circ} \mathrm{CA}$ BTDC main injection timing.

3.5. Confirmation Experiment. The last step in Taguchi optimization method is to conduct confirmation experiments with the optimum combination of influencing factors for validating the improvement in the response variable by comparing it with the original baseline condition. After conducting the confirmation experiment, optimized engine reduces by at least $70 \%$ for $\mathrm{NO}_{x}$ and $20 \%$ in soot formation. As for ISFC, a slight reduction of $1 \%$ compared to original baseline engine is shown.

Figure 9 shows in-cylinder equivalence ratio and emission distributions with respect to optimized and original baseline case by simulations. As is seen, in the optimized case, after the spray impinges on the top of the piston bowl at end of the main injection, equivalence ratio distributions indicate a more homogeneous mixture in-cylinder than fuel concentration distributions in original baseline case. It is also illustrated that the fuel-air mixing was enhanced as a result of the application of optimum parameter combination. In the case of comparison of emission distributions between optimized and original case, as shown in Figure 9, it is found that significant concentrations of $\mathrm{NO}_{x}$ and soot emissions are found in regions corresponding to emission formation zones in original baseline case. However, most of $\mathrm{NO}_{x}$ and soot emissions are eliminated in the optimized case, because of improved mixture formation and combustion processes [28].

\section{Conclusions}

In the present work, CFD simulation together with the Taguchi and the ANOVA technique was used to investigate the combined effect of EGR rate, pilot fuel quantity, and main injection timing on the $\mathrm{NO}_{x}$, soot, and ISFC in a diesel engine at $2000 \mathrm{r} / \mathrm{min}$, 50\% load, with minimum number of experimental work. The following conclusions are drawn from the investigation.

(1) According to the analysis of $S / N$ curves, it is concluded that the $S / N$ ratio of factor EGR rate varies largely and three influencing factors show a consistent trend in affecting the $\mathrm{NO}_{x}$ varying with the levels. In addition, EGR and main injection timing have a contrary influence for soot as compared to $\mathrm{NO}_{x}$. In the case of soot emissions and ISFC, they can be reduced simultaneously by choosing the same factors and levels for each other.

(2) The ANOVA results illustrated that EGR is the most influencing factor on $\mathrm{NO}_{x}$. For soot emission and ISFC, the greatest influence factor is main injection timing. However, pilot fuel quantity does not have important effects on all objectives.
(3) The optimum combination of factors and levels for the chosen response variables are at $27 \%$ EGR rate, $27.2 \%$ pilot fuel quantity, and $4^{\circ} \mathrm{CA}$ BTDC main injection timing. Confirmation experiment was carried out to validate the accuracy of the CFD simulation results. And the engine with optimized combination reduces by at least $70 \%$ for $\mathrm{NO}_{x}$ and $20 \%$ in soot formation. As for ISFC, a slight reduction of $1 \%$ compared to original baseline engine was shown.

(4) The combination of the CFD simulation, the Taguchi method, and the ANOVA technique is found to be a good method, which can significantly save time and cost, to find optimum combination for low $\mathrm{NO}_{x}$, soot, and ISFC in a light duty diesel engine.

\section{Conflict of Interests}

The authors declare that there is no conflict of interests regarding the publication of this paper.

\section{Acknowledgment}

This work is supported by the National Natural Science Foundation of China (Grant no. 51176064).

\section{References}

[1] S. Saravanan, G. Nagarajan, and S. Sampath, "Multi response optimization of NOx emission of a stationary diesel engine," Fuel, vol. 89, no. 11, pp. 3235-3240, 2010.

[2] H. Wu and Z. Wu, "Combustion characteristics and optimal factors determination with Taguchi method for diesel engines port-injecting hydrogen," Energy, vol. 47, no. 1, pp. 411-420, 2012.

[3] C. Krishnan, Y. Vinod, and C. Sudhindra, "Optimization of fuel injection parameters for meeting euro III exhaust emission norms on a heavy duty diesel engine using Taguchi technique," SAE Technical Paper 2008-01-1610, 2008.

[4] R. D. Reitz, "Directions in internal combustion engine research," Combustion and Flame, vol. 160, no. 1, pp. 1-8, 2013.

[5] W. Park, J. Y. Lee, K. Min, J. Yu, S. Park, and S. H. Cho, "Prediction of real-time NO based on the in-cylinder pressure in Diesel engines," Proceedings of the Combustion Institute, vol. 34, no. 2, pp. 3075-3082, 2013.

[6] S. Kumar and M. K. Chauhan, "Numerical modeling of compression ignition engine: a review," Renewable and Sustainable Energy Reviews, vol. 19, pp. 517-530, 2013.

[7] S. Z. Rezaei, F. Zhang, H. Xu, A. Ghafourian, J. M. Herreros, and S. Shuai, "Investigation of two-stage split-injection strategies for a Dieseline fuelled PPCI engine," Fuel, vol. 107, pp. 299-308, 2013.

[8] Q.-C. Hsu and A. T. Do, "Minimum porosity formation in pressure die casting by Taguchi method," Mathematical Problems in Engineering, vol. 2013, Article ID 920865, 9 pages, 2013.

[9] S. Thipprakmas, "Application of Taguchi technique to investigation of geometry and position of V-ring indenter in fineblanking process," Materials and Design, vol. 31, no. 5, pp. 24962500, 2010. 
[10] A. Diez and H. Zhao, "Investigation of split injection in a single cylinder optical diesel engine," SAE Technical Paper 2010-010605, 2010.

[11] S. Saravanan, G. Nagarajan, and S. Sampath, "Combined effect of injection timing, EGR and injection pressure in $\mathrm{NO}_{x}$ control of a stationary diesel engine fuelled with crude rice bran oil methyl ester," Fuel, vol. 104, pp. 409-416, 2013.

[12] N. P. Komninos and C. D. Rakopoulos, "Modeling HCCI combustion of biofuels: a review," Renewable and Sustainable Energy Reviews, vol. 16, no. 3, pp. 1588-1610, 2012.

[13] R. Mobasheri, Z. Peng, and S. M. Mirsalim, "Analysis the effect of advanced injection strategies on engine performance and pollutant emissions in a heavy duty DI-diesel engine by CFD modeling," International Journal of Heat and Fluid Flow, vol. 33, no. 1, pp. 59-69, 2012.

[14] O. Colin and A. Benkenida, "The 3-zones Extended Coherent Flame Model (ECFM3Z) for computing premixed/diffusion combustion," Oil and Gas Science and Technology, vol. 59, no. 6, pp. 593-609, 2004.

[15] K. Truffin and O. Colin, "Auto-ignition model based on tabulated detailed kinetics and presumed temperature PDFapplication to internal combustion engine controlled by thermal stratifications," International Journal of Heat and Mass Transfer, vol. 54, no. 23-24, pp. 4885-4894, 2011.

[16] AVL LIST GmbH, AVL FIRE Users Guide-Version 2013.0, AVL LIST GmbH, Graz, Austria, 2013.

[17] K. Hanjalić, M. Popovac, and M. Hadžiabdić, "A robust nearwall elliptic-relaxation eddy-viscosity turbulence model for CFD," International Journal of Heat and Fluid Flow, vol. 25, no. 6, pp. 1047-1051, 2004.

[18] Z. Peng, B. Liu, W. Wang, and L. Lu, "CFD investigation into diesel PCCI combustion with optimized fuel injection," Energies, vol. 4, no. 3, pp. 517-531, 2011.

[19] S. Thipprakmas and W. Phanitwong, "Process parameter design of spring-back and spring-go in V-bending process using Taguchi technique," Materials and Design, vol. 32, no. 8-9, pp. 4430-4436, 2011.

[20] D. H. Lee, J. S. Park, M. R. Ryu, and J. H. Park, "Development of a highly efficient low-emission diesel engine-powered cogeneration system and its optimization using Taguchi method," Applied Thermal Engineering, vol. 50, no. 1, pp. 491-495, 2013.

[21] S. Hajireza, G. Regner, A. Christie, M. Egert, and H. Mittermaier, "Application of CFD modeling in combustion bowl assessment of diesel engines using DoE methodology," SAE Technical Paper 2006-01-3330, 2006.

[22] H. E. Saleh, "Effect of exhaust gas recirculation on diesel engine nitrogen oxide reduction operating with jojoba methyl ester," Renewable Energy, vol. 34, no. 10, pp. 2178-2186, 2009.

[23] J. Zhang, Particle matter emission control and related issues for diesel engines [Ph.D. thesis], University of Birmingham, Birmingham, UK, 2011.

[24] K. Okude, K. Mori, S. Shiino, K. Yamada, and Y. Matsumoto, "Effects of multiple injections on diesel emission and combustion characteristics," SAE Technical Paper 2007-01-4178, 2007.

[25] M. Gomaa, A. J. Alimin, and K. A. Kamaruddin, "Trade-off between NOx, soot and EGR rates for an IDI diesel engine fuelled with JB5," Journal of Applied Sciences, vol. 11, no. 11, pp. 1987-1993, 2011.

[26] D. Agarwal, S. K. Singh, and A. K. Agarwal, "Effect of Exhaust Gas Recirculation (EGR) on performance, emissions, deposits and durability of a constant speed compression ignition engine," Applied Energy, vol. 88, no. 8, pp. 2900-2907, 2011.
[27] S. N. Soid and Z. A. Zainal, "Spray and combustion characterization for internal combustion engines using optical measuring techniques-a review," Energy, vol. 36, no. 2, pp. 724-741, 2011.

[28] D. Kim and S. Park, "Optimization of injection strategy to reduce fuel consumption for stoichiometric diesel combustion," Fuel, vol. 93, pp. 229-237, 2012. 


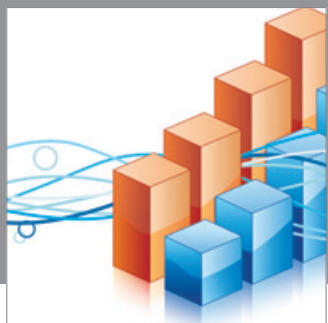

Advances in

Operations Research

mansans

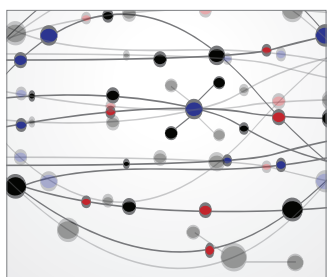

The Scientific World Journal
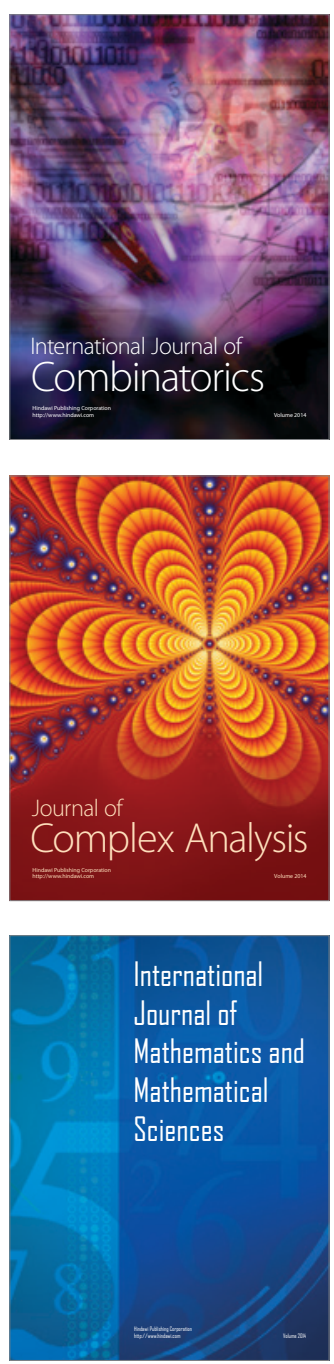
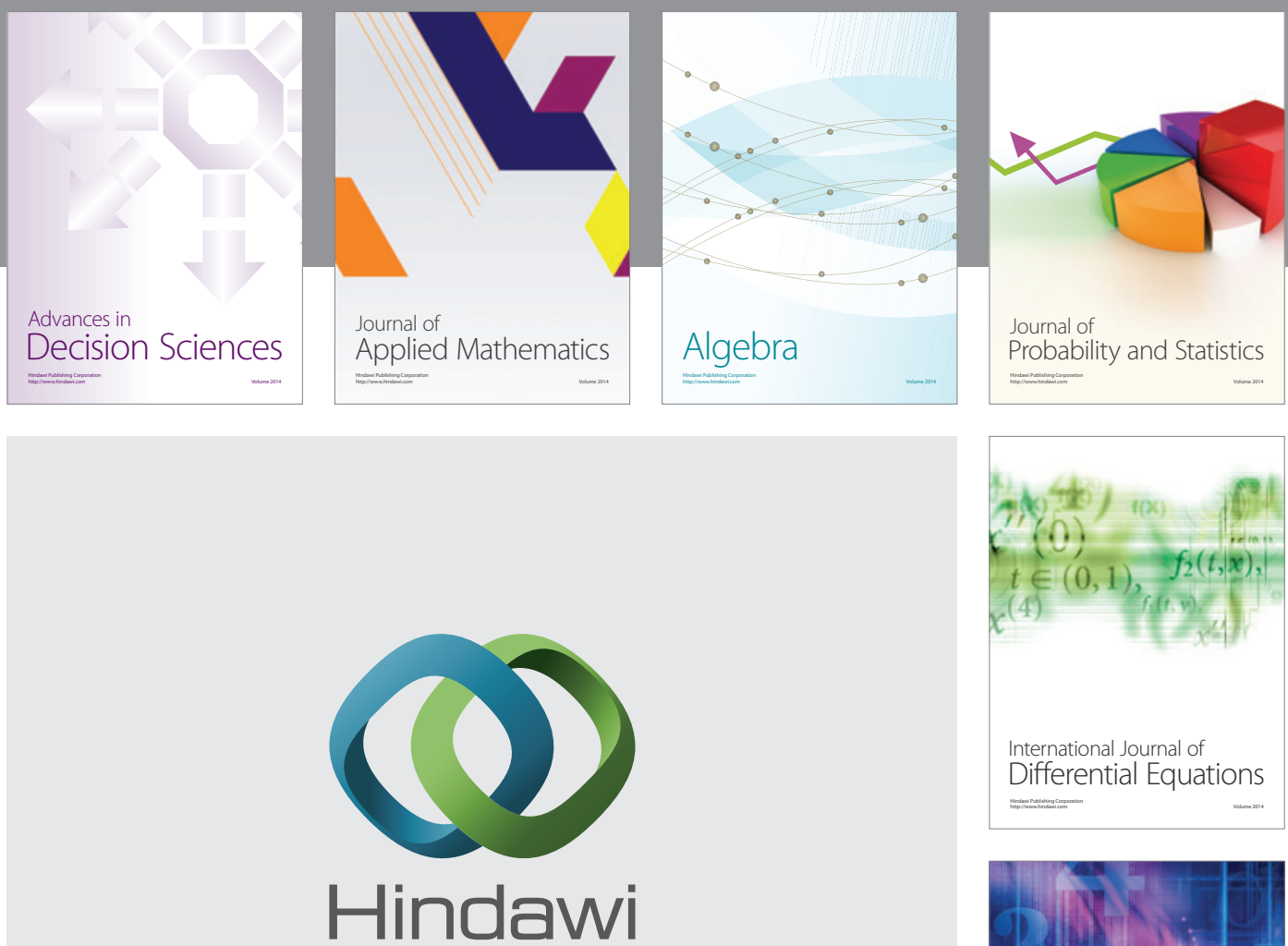

Submit your manuscripts at http://www.hindawi.com
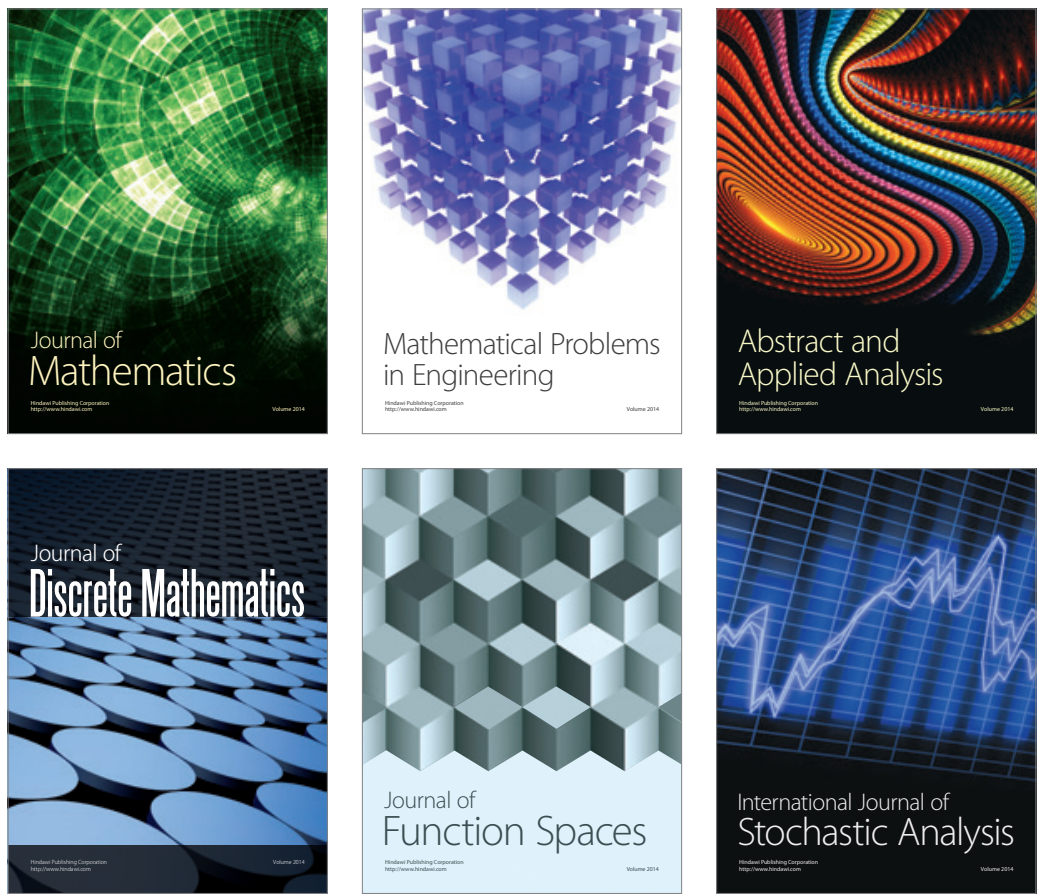

Journal of

Function Spaces

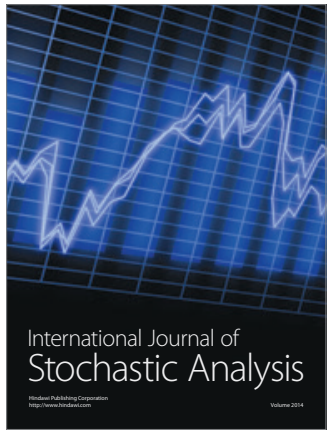

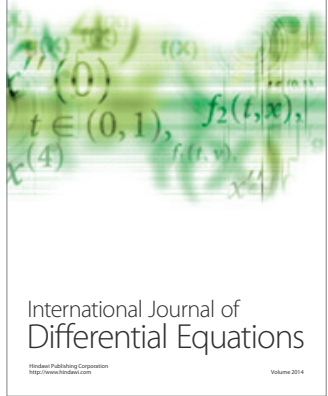
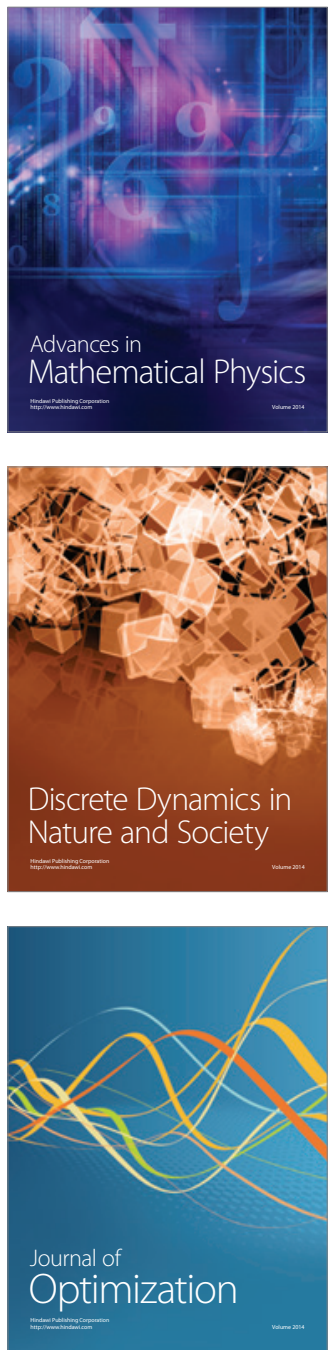